\title{
Can we predict the direction of marine primary production change under global warming?
}

\author{
J. Taucher ${ }^{1}$ and A. Oschlies ${ }^{1}$ \\ Received 22 October 2010; revised 1 December 2010; accepted 6 December 2010; published 21 January 2011.
}

[1] A global Earth System model is employed to investigate the role of direct temperature effects in the response of marine ecosystems to climate change. While model configurations with and without consideration of explicit temperature effects can reproduce observed current biogeochemical tracer distributions and estimated carbon export about equally well, carbon flow through the model ecosystem reveals strong temperature sensitivities. Depending on whether biological processes are assumed temperature sensitive or not, simulated marine net primary production (NPP) increases or decreases under projected climate change driven by a business-as-usual $\mathrm{CO}_{2}$ emission scenario for the 21 st century. This suggests that indirect temperature effects such as changes in the supply of nutrients and light are not the only relevant factors to be considered when modeling the response of marine ecosystems to climate change. A better understanding of direct temperature effects on marine ecosystems is required before even the direction of change in NPP can be reliably predicted. Citation: Taucher, J., and A. Oschlies (2011), Can we predict the direction of marine primary production change under global warming?, Geophys. Res. Lett., 38, L02603, doi:10.1029/ 2010 GL045934.

\section{Introduction}

[2] Climate change is expected to have diverse impacts on marine ecosystems [Riebesell et al., 2009]. Estimates of possible future changes in marine are generally based on numerical models. Most model studies addressing the response of marine ecosystems and biogeochemistry to climate change have, so far, focused on the effects of changes in nutrient or light availability. These are mostly attributable to enhanced stratification and weaker vertical mixing [Bopp et al., 2001; Boyd and Doney, 2002; Plattner et al., 2001] and are thus indirect effects of rising surface temperatures. An analysis of different biogeochemical climate models found a coherent decline of both NPP and export production under projected 21 st century global warming [Steinacher et al., 2010]. In contrast, Sarmiento et al. [2004] found an increase in projected 21 st century NPP, using a semiempirical approach, which combines climate model projections and satellite-based primary production algorithms. They identified the temperature sensitivities of the primary production algorithm as the main cause for the predicted increase in primary production.

\footnotetext{
${ }^{1}$ Leibniz Institute for Marine Sciences at Kiel University (IFMGEOMAR), Kiel, Germany.
}

Copyright 2011 by the American Geophysical Union. 0094-8276/11/2010GL045934
[3] Up to now, modeling studies have paid only little attention to the direct biological impacts of higher temperatures in simulations of global warming, although experimental evidence suggests a positive correlation between temperature and phytoplankton growth [Duarte, 1995; Eppley, 1972] and effects of elevated temperatures at the ecosystem level [Muren et al., 2005; Wohlers et al., 2009]. Yet, the description of direct temperature effects differs considerably among different models [Steinacher et al., 2010]. Here we specifically investigate the sensitivity of simulated 21 st century's changes in marine primary production to the consideration of direct temperature effects on metabolic processes.

\section{Methods}

[4] The model employed is the University of Victoria (UVic) global Earth system model [Schmittner et al., 2008; Weaver et al., 2001]. It includes a simple NPZD type marine ecosystem model with the two nutrients phosphate and nitrate, two phytoplankton classes (nitrogen fixers and other phytoplankton) and one zooplankton type. Furthermore it contains a parameterization of fast nutrient recycling as a representation of the microbial loop and the cycling of dissolved organic matter [Schartau and Oschlies, 2003]. In the standard version [Schmittner et al., 2008], hereafter called TEMP, biological production and remineralization processes depend on temperature via an Eppley formula [Eppley, 1972] with a $Q_{10}$ value of 1.88. In a sensitivity experiment (NOTEMP), all temperature-dependent rate coefficients are replaced by constant values.

[5] Rate constants of the NOTEMP run are chosen as fluxweighted global averages of the temperature-dependent rates of the TEMP experiment. For instance, the maximum growth rate of phytoplankton is directly dependent on temperature:

$$
J_{\max }=a \times b^{c T}
$$

The term $b^{c T}$ is calculated with temperature $T$ and the sensitivity parameters $b=1.066$ and $c^{\circ} \mathrm{C}=1.0$. In configuration NOTEMP the temperature-sensitivity $c$ is 0.0 , and thus $b^{c T}=1.0$. To ensure that global biogeochemical fluxes are as close as possible to those of experiment TEMP, other parameters describing the respective biological processes are readjusted by the process-weighted global-mean temperature term $b^{c \bar{T}_{\text {proc }}}$ with $\bar{T}_{\text {proc }}$, in the case of NPP, given by

$$
\bar{T}_{N P P}=\frac{(\overline{N P P \times \text { Temperature }})}{\overline{N P P}}
$$


Table 1. Changes of Model Parameters From Configuration TEMP to NOTEMP

\begin{tabular}{|c|c|c|c|}
\hline Parameter & Symbol & TEMP & NOTEMP \\
\hline \multicolumn{4}{|c|}{ Phytoplankton $\left(P_{o} . P_{D}\right)$} \\
\hline Maximum growth rate at $0^{\circ} \mathrm{C}\left[\mathrm{day}^{-1}\right]$ & $a$ & 0.2 & 0.71 \\
\hline $\begin{array}{l}\text { Temperature dependence of } \\
\text { maximum growth rate }\end{array}$ & $c^{\circ} \mathrm{C}$ & 1.0 & 0.0 \\
\hline $\begin{array}{l}\text { Linear mortality coefficient (fast } \\
\text { recycling) }\left[\text { day }^{-1}\right]\end{array}$ & $\mu_{P 0}$ & 0.014 & 0.0545 \\
\hline $\begin{array}{l}\text { Handicap of diazotrophs w.r.t. other } \\
\text { phytoplankton }\end{array}$ & $c_{D}$ & 0.5 & 0.25 \\
\hline \multicolumn{3}{|c|}{ Zooplankton (Z) } & 0.0385 \\
\hline \multicolumn{4}{|l|}{ Detritus (D) } \\
\hline Remineralization rate $\left[\mathrm{day}^{-1}\right]$ & $\mu_{D 0}$ & 0.048 & 0.139 \\
\hline
\end{tabular}

Thereby parameter $a$ is increased from $0.2 \mathrm{~d}^{-1}$ in run TEMP to $0.71 \mathrm{~d}^{-1}$ in run NOTEMP. All parameter changes are listed in Table 1.

[6] After a spin-up of 4,000 years with preindustrial boundary conditions (e.g., insolation, fixed atmospheric $\mathrm{CO}_{2}$ of $280 \mathrm{ppm}$ ), the models are forced using fossil fuel and land use carbon emissions as well as solar, volcanic and anthropogenic aerosol forcing reconstructed from different datasets for the period 1765 to 2000 [Schmittner et al., 2008]. From year 2000 onwards, the model is forced by anthropogenic $\mathrm{CO}_{2}$ emissions following the IPCC SRES A2 ("business-as-usual") scenario. Consequently, both model simulations account for indirect temperature effects of $\mathrm{CO}_{2}$ driven global warming, such as changes in circulation and stratification and associated impacts on nutrient and light supply. However only model TEMP accounts for the direct effects of elevated temperatures on metabolic rates.

\section{Results and Discussion}

\subsection{Present Day Conditions}

[7] Simulated nutrient, carbon, and oxygen fields in both models agree well with observations (Figure 1). Compared to data from the World Ocean Atlas [Garcia et al., 2006] the global average root mean square (RMS) error for phosphate is $0.138 \mathrm{mmol} \mathrm{m}^{-3}$ in run TEMP and $0.157 \mathrm{mmol} \mathrm{m}^{-3}$ in model NOTEMP. This RMS error is at the lower end of errors found in previous modeling studies [Doney et al., 2009; Kriest et al., 2010]. Global marine net primary production simulated for the year 2000 amounts to $49.0 \mathrm{GtC} \mathrm{yr}^{-1}$ in

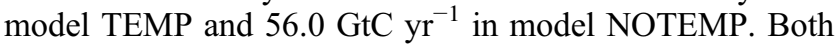
numbers are in good agreement with diverse satellite-based

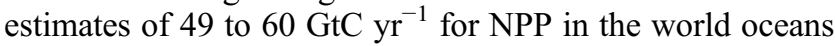
[Behrenfeld et al., 2006; Carr et al., 2006]. Datasets on NPP used here (Figure 2a) give $54.1 \mathrm{GtC} \mathrm{yr}^{-1}$ [Behrenfeld and Falkowski, 1997] and $56.7 \mathrm{GtC} \mathrm{yr}^{-1}$ [Westberry et al., 2008]. Export production is also of similar magnitude in both model configurations, reaching $8.7 \mathrm{GtC} \mathrm{yr}^{-1}$ in run TEMP and $11.3 \mathrm{GtC} \mathrm{yr}^{-1}$ in run NOTEMP (Figure 2d). These numbers also agree with observation-based estimates from previous studies [Oschlies, 2001; Schlitzer, 2004].

[8] Despite these similarities on the global scale, the spatial patterns and underlying controls of the various biological processes show some major differences between the two model configurations (Figures 2a-2d): In configuration
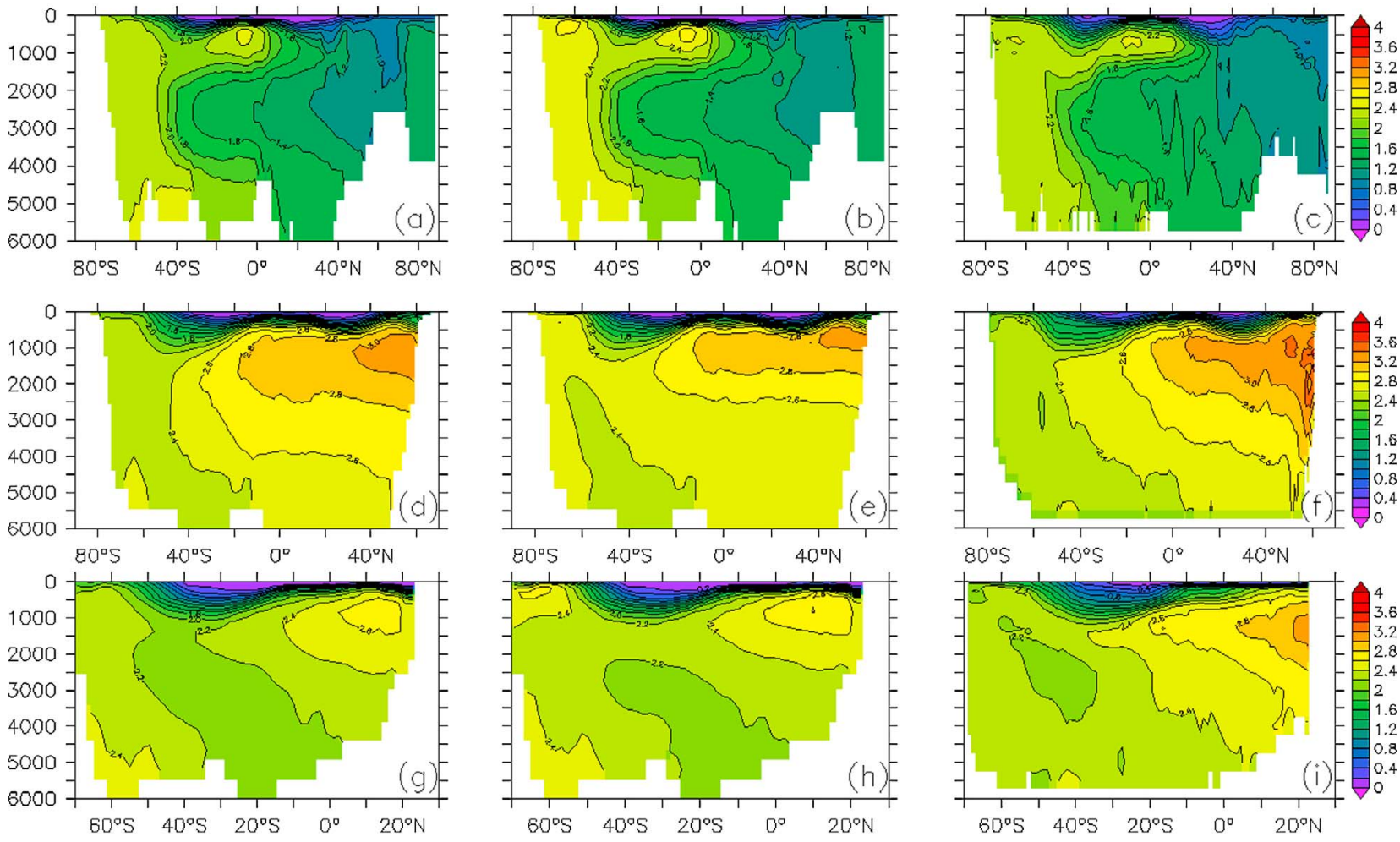

Figure 1. Depth-latitude sections of phosphate concentrations $\left[\mathrm{mmol} \mathrm{m}^{-3}\right]$ in the $(\mathrm{a}-\mathrm{c})$ Atlantic, $(\mathrm{d}-\mathrm{f})$ Pacific and $(\mathrm{g}-\mathrm{i})$ Indian Ocean in model (left) TEMP, (middle) NOTEMP and (right) from World Ocean Atlas [Garcia et al., 2006] data. 

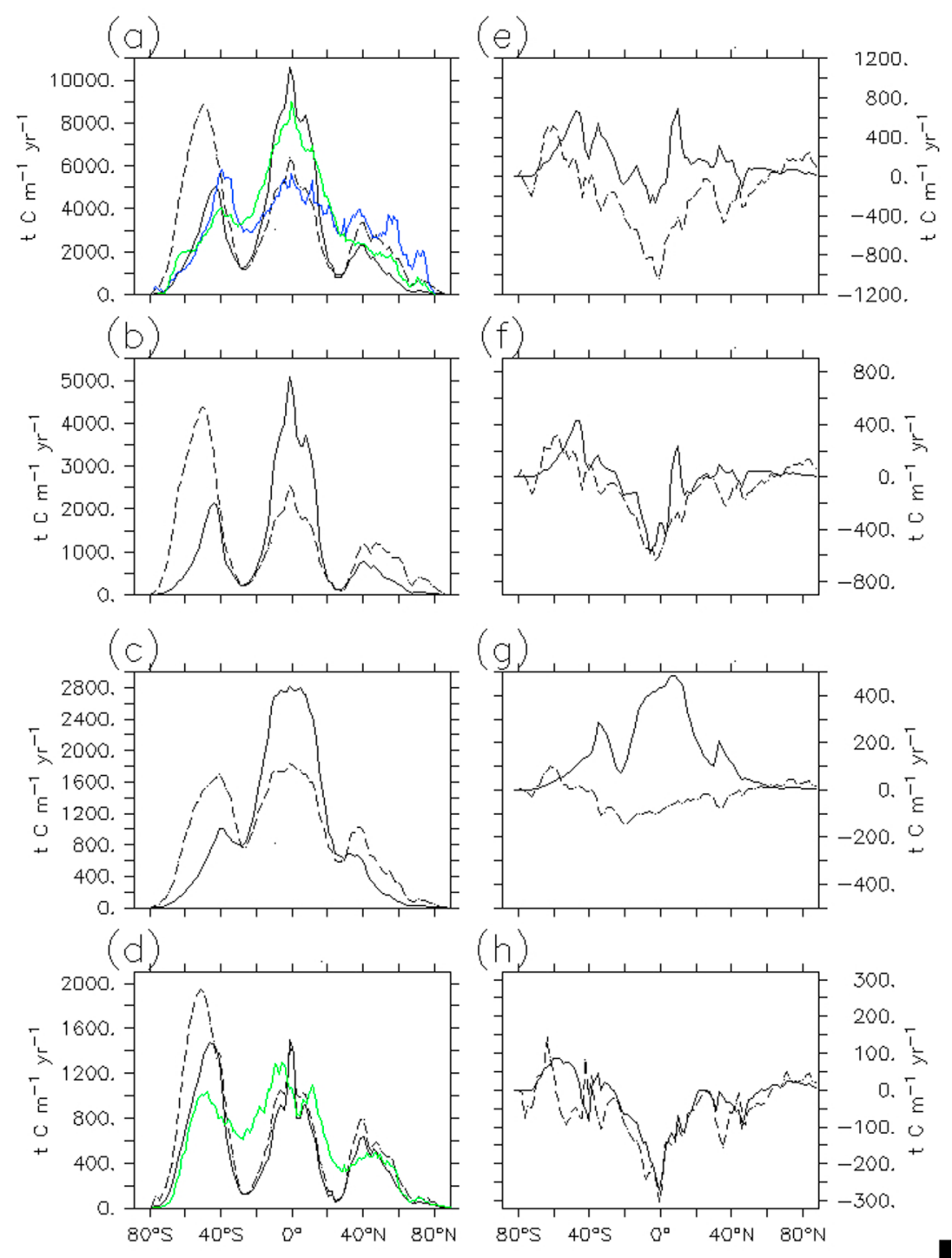

Figure 2. (a-d) Zonal distribution of marine ecosystem processes in the model with (solid) and without temperature dependence (dashed) in the year 2000 and (e-h) their respective change from 2000 through 2100. From top: Net Primary Production [ $\left.\mathrm{tC}^{\circ} \mathrm{lat}^{-1} \mathrm{yr}^{-1}\right]$, Remineralization of detritus $\left[\mathrm{tC} \mathrm{m}^{-1} \mathrm{yr}^{-1}\right]$, Fast Recycling $\left[\mathrm{tC} \mathrm{m}^{-1} \mathrm{yr}^{-1}\right]$, Export of organic matter (including turbulent mixing) $\left[\mathrm{tC} \mathrm{m}^{-1} \mathrm{yr}^{-1}\right]$. NPP (Figure 2a) includes SeaWiFS estimates using VGPM [Behrenfeld and Falkowski, 1997] (blue) and CBPM2 [Westberry et al., 2008] (green) algorithms, and export of organic matter (Figure 2d) includes observation-based export estimates [Schlitzer, 2002, 2004] (green).

TEMP, high values of NPP in the tropical oceans are accompanied by high recycling rates, especially remineralization and fast recycling via the microbial loop from phytoplankton back to dissolved inorganic nutrients, since all these processes occur faster at higher temperatures. Essentially, a short circuit is established, in which NPP is again fueled by rapidly regenerated nutrients and relatively little biomass is exported to depth ( $10 \%$ of NPP). In run NOTEMP, the absence of a direct positive effect of temperature on metabolic rates yields lower tropical NPP, lower remineralization and less intense recycling of phytoplankton biomass back to nutrients. However, simulated export production in the tropical ocean turns out to be even higher in run NOTEMP, as less biomass is lost through recycling processes, leaving a higher fraction of NPP $(\sim 19 \%)$ avail- able for export to depth. At high latitudes the pattern is reversed. NPP reaches high levels in run NOTEMP. However, a large portion of organic matter is recycled in the surface ocean, as there is no slowdown by low water temperatures. Consequently, the amount of organic matter that is exported to depth is relatively small compared to the high level of NPP $(\sim 13 \%)$. In run TEMP, the high-latitude ecosystem works at a much lower level of biomass production. NPP is inhibited by low temperatures and reaches not even a quarter of high-latitude NPP of run NOTEMP. All recycling processes are also slowed down by low temperatures in run TEMP, channeling a relatively large fraction of simulated high-latitude NPP ( $33 \%)$ into export of sinking particles. Regional differences in export production between the two model configurations are relatively small compared to the 

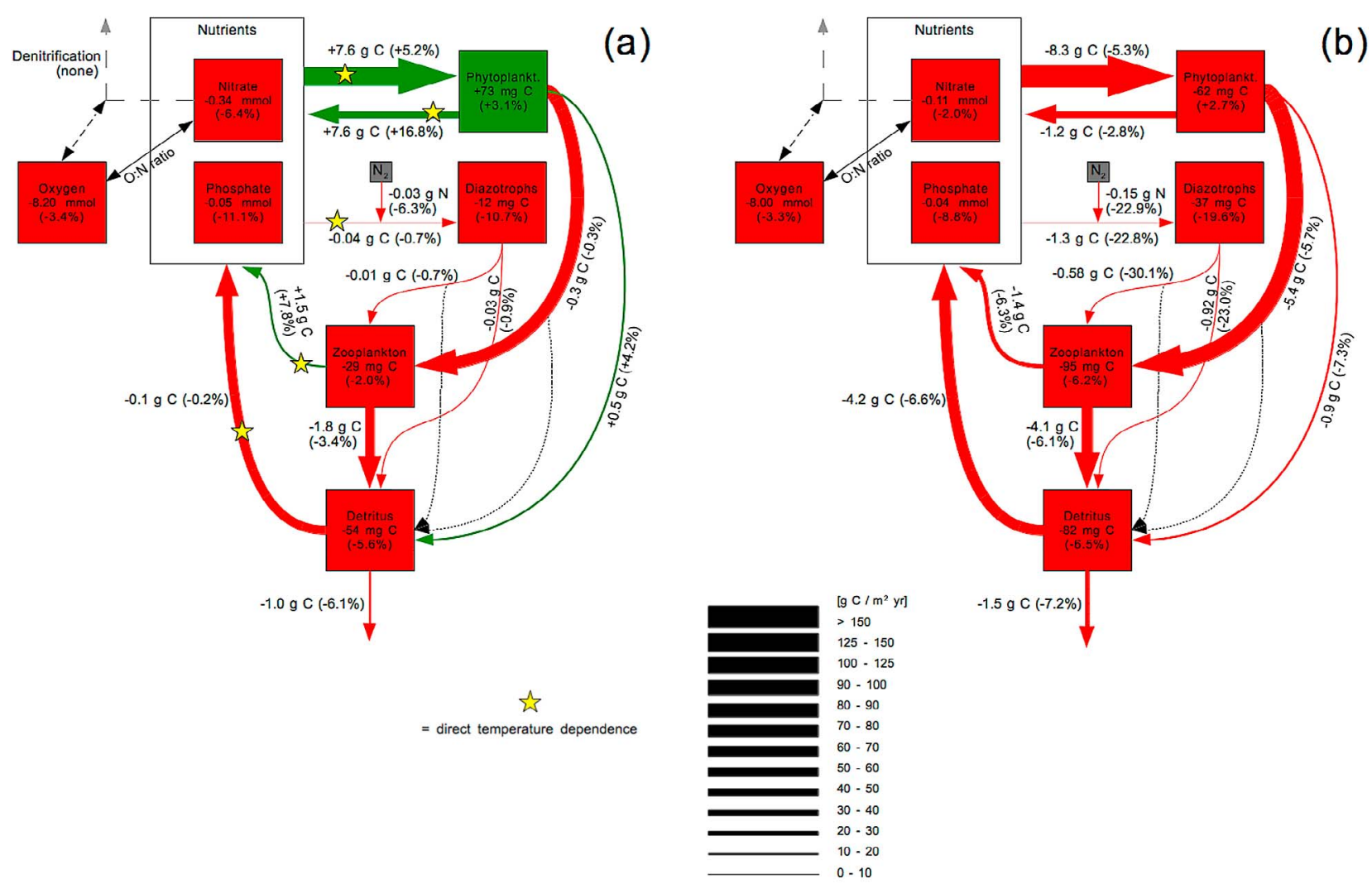

\section{b)}

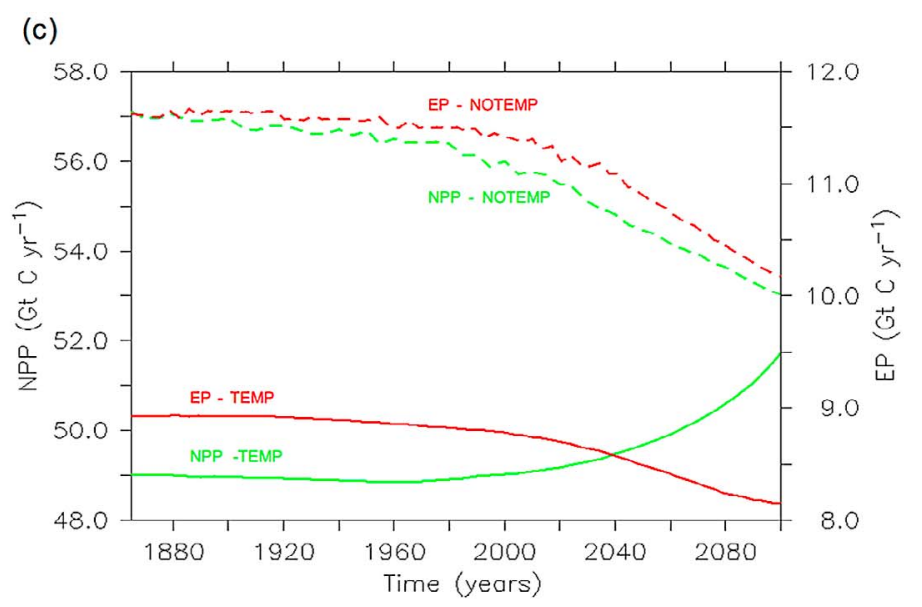

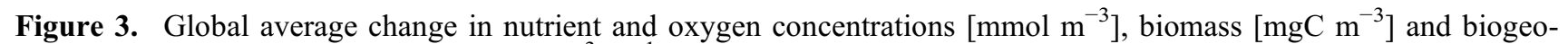
chemical flows in carbon equivalents $\left[\mathrm{gC} \mathrm{m}^{-3} \mathrm{yr}^{-1}\right]$ in the surface ocean $(0-130 \mathrm{~m})$ in model (a) TEMP and (b) NOTEMP for the period 2000 to 2100. Percentage change given in brackets. (c) Timeseries of global Net Primary Production (NPP) and Export Production (EP) of organic matter out of the upper $130 \mathrm{~m}$ in model TEMP and NOTEMP.

pronounced differences in NPP. Also, NPP and export production in both models compare about equally well with observation-based estimates (Figures $2 \mathrm{a}$ and $2 \mathrm{~d}$ ).

\subsection{Response to Climate Change}

[9] Following the SRES A2 emission scenario, simulated global sea surface temperatures increase by $2.0{ }^{\circ} \mathrm{C}$ in the 21 st century [Schmittner et al., 2008]. Physical changes of the ocean, like enhanced thermal stratification, reduced upwelling and weaker vertical mixing lead to reduced sup- ply of nutrients to the surface ocean in both models. Being closely tied to simulated nutrient supply, global export production responds very similarly in both model configurations over the period 2000-2100, with a decrease from

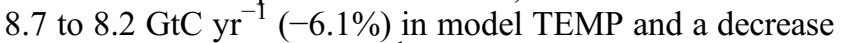
from 11.3 to $10.3 \mathrm{GtC} \mathrm{yr}^{-1}(-7.2 \%)$ in model NOTEMP (Figure 3). The response also shows a similar spatial pattern in both model simulations (Figure 2h). In contrast, changes in individual ecological processes turn out to differ considerably among the two model configurations: In run 
NOTEMP, all globally-averaged carbon and nitrogen fluxes associated with any biological process decrease in response to climate change (Figure $3 \mathrm{~b}$ ). In particular, simulated annual NPP decreases from 56.0 to $53.0 \mathrm{GtC} \mathrm{yr}^{-1}$ from year 2000 to $2100(-5.3 \%)$. This change is directly linked to the decrease in nutrient supply. In contrast, in configuration TEMP simulated global NPP increases from 49.0 to $51.7 \mathrm{GtC} \mathrm{yr}^{-1}$ $(+5.2 \%)$ during the same period (Figure 3a) despite the decline in export production. Besides NPP, fast recycling of phytoplankton increases significantly from 16.0 to $18.7 \mathrm{GtC}$ $\mathrm{yr}^{-1}(+16.9 \%)$ in model TEMP. This indicates a faster spinning of the microbial loop under elevated temperatures, and a corresponding increase in regenerated production.

[10] Latitudinal differences in the response to simulated climate-induced changes in metabolic rates are shown in Figures 2e-2h: At high latitudes NPP and phytoplankton biomass moderately increase in both model configurations. This is mainly due to the shoaling of the mixed layer, the retreat of sea ice and a longer growing season. The increase in high-latitude NPP is also accompanied by an increase in export production in both models. Major differences between the two models occur at low and intermediate latitudes. In model TEMP, both NPP and phytoplankton biomass increase in most parts of the tropical and subtropical oceans (Figure 2e). The strongest response can be observed for fast recycling from phytoplankton back to inorganic nutrients (Figure 2f). Its acceleration is tightly coupled to NPP, since the build-up of biomass provides the substrate for fast recycling, which in turn restores nutrients and thereby fuels NPP. At the same time, simulated export production remains closely tied to nutrient supply, which is affected only indirectly by temperature and hence shows a similar decrease under global warming in runs TEMP and NOTEMP. However, in run NOTEMP, both NPP and biomass of phytoplankton also show a decrease in the tropical and subtropical oceans. Without the enhancement of recycling processes by higher temperatures, regenerated production decreases along with new production (Figures 2e and 2h). Consequently, spatial differences in the simulated response of NPP among the two model configurations correspond to differences in the simulated response of the microbial loop to global warming.

[11] The global-warming induced increase in NPP in configuration TEMP appears contradictory to the results of studies by Gregg et al. [2003] and Behrenfeld et al. [2006] which are based on satellite measurements and suggest a predominantly negative correlation of increasing temperatures and marine NPP. However, these studies cover a relatively short time span and do not disentangle direct and indirect effects of temperature changes. When satellite NPP algorithms were applied to changes in the physical environment projected for the end of the 21 st century, Sarmiento et al. [2004] inferred an increase in marine NPP in response to warming, which would agree with the results of our model configuration TEMP.

[12] The results of model TEMP also appear to agree better with empirical evidence on the relationship between temperature and phytoplankton growth [Eppley, 1972; Moisan et al., 2002] and with observed responses of marine ecosystem processes to elevated temperatures. Recent mesocosm experiments revealed a clear effect of elevated temperatures on ecosystem functioning and carbon cycling, with a generally stronger temperature dependence of heterotrophic pro- cesses [Muren et al., 2005; Wohlers et al., 2009]. While a coherent effect of elevated temperatures on primary production could not be observed in these experiments, the stronger response of respiration relative to autotrophic production to elevated temperatures favors a shift towards a more heterotrophic system and associated lower vertical export of organic matter, which is consistent with the results of model TEMP.

\section{Conclusions}

[13] The model experiments presented here reveal that temperature sensitivities of metabolic rates have the potential to play an important role in controlling marine ecosystem processes and their response to climate change. Depending on whether or not metabolic rates are assumed temperature dependent in the model, not only the magnitude, but even the direction of global-warming induced change is different for global NPP and the associated cycling of carbon and nutrients through the model ecosystem. Our model results also show that it is possible to adjust models with and without explicit temperature dependence about equally well to observed biogeochemical tracer distributions, which alone do not seem to provide sufficient information to judge which of the two model configurations TEMP or NOTEMP and, by inference, which sign of projected 21 st century NPP change is more realistic.

[14] In contrast to NPP, simulated export production and thereby the effective drawdown of carbon appear closely tied to the physically driven supply of nutrients and respond almost equally to climate change, regardless of whether direct temperature effects on biology are included in the model or not. In this regard, our results are consistent with results from previous studies [Bopp et al., 2001; Cox et al., 2000; Fung et al., 2005], which all project a decrease in export production in response to global warming. However, a number of global models also simulate a future decrease in primary production [Steinacher et al., 2010], which is not found in our model configuration TEMP, where elevated temperatures lead to higher NPP and accelerated carbon cycling. Our results also indicate that changes in NPP are closely linked to the temperature sensitivities of recycling processes and especially the microbial loop, which are not considered in most other global models [Steinacher et al., 2010]. However, the intricate balance between production and respiration under increasing temperatures is still not understood properly and needs further research [Riebesell et al., 2009].

[15] Our study has shown that the simulated response of NPP to climate change depends on the assumptions made about the temperature dependencies of metabolic processes. Here we used the same temperature function for both autotrophic and heterotrophic processes. However, marine phytoplankton growth and photosynthesis are mainly controlled by light supply and nutrient availability and are therefore commonly assumed to show a weaker response to elevated temperatures than heterotrophic processes such as bacterial degradation [Pomeroy and Wiebe, 2001; Riebesell et al., 2009]. Including these considerations in refined models might further accelerate the simulated microbial loop and thereby enhance the discrepancy in the responses of NPP and export production to global warming. We conclude, that a better understanding and model representation of direct 
temperature effects on biological processes is required in order to obtain robust estimates of even the direction of marine primary production changes under global warming.

[16] Acknowledgment. This study was supported by the Deutsche Forschungsgemeinschaft (DFG).

\section{References}

Behrenfeld, M. J., and P. G. Falkowski (1997), Photosynthetic rates derived from satellite-based chlorophyll concentration, Limnol. Oceanogr., 42(1), 1-20, doi:10.4319/1o.1997.42.1.0001.

Behrenfeld, M. J., R. T. O’Malley, D. A. Siegel, C. R. McClain, J. L. Sarmiento, G. C. Feldman, A. J. Milligan, P. G. Falkowski, R. M. Letelier, and E. S. Boss (2006), Climate-driven trends in contemporary ocean productivity, Nature, 444(7120), 752-755, doi:10.1038/nature05317.

Bopp, L., P. Monfray, O. Aumont, J. L. Dufresne, H. Le Treut, G. Madec, L. Terray, and J. C. Orr (2001), Potential impact of climate change on marine export production, Global Biogeochem. Cycles, 15(1), 81-99, doi:10.1029/1999GB001256.

Boyd, P. W., and S. C. Doney (2002), Modelling regional responses by marine pelagic ecosystems to global climate change, Geophys. Res. Lett., 29(16), 1806, doi:10.1029/2001GL014130.

Carr, M. E., et al. (2006), A comparison of global estimates of marine primary production from ocean color, Deep Sea Res., Part II, 53(5-7), 741-770, doi:10.1016/j.dsr2.2006.01.028.

Cox, P. M., R. A. Betts, C. D. Jones, S. A. Spall, and I. J. Totterdell (2000), Acceleration of global warming due to carbon-cycle feedbacks in a coupled climate model, Nature, 408(6809), 184-187, doi:10.1038/35041539.

Doney, S. C., I. Lima, J. K. Moore, K. Lindsay, M. J. Behrenfeld, T. K. Westberry, N. Mahowald, D. M. Glover, and T. Takahashi (2009), Skill metrics for confronting global upper ocean ecosystem-biogeochemistry models against field and remote sensing data, J. Mar. Syst., 76(1-2), 95-112, doi:10.1016/j.jmarsys.2008.05.015.

Duarte, P. (1995), A mechanistic model of the effects of light and temperature on algal primary productivity, Ecol. Modell., 82(2), 151-160, doi:10.1016/0304-3800(94)00088-Y.

Eppley, R. W. (1972), Temperature and phytoplankton growth in sea, Fish. Bull., 70(4), 1063-1085.

Fung, I. Y., S. C. Doney, K. Lindsay, and J. John (2005), Evolution of carbon sinks in a changing climate, Proc. Natl. Acad. Sci. U. S. A., 102(32), 11,201-11,206, doi:10.1073/pnas.0504949102.

Garcia, H. E., R. A. Locarnini, T. P. Boyer, and J. I. Antonov (2006), Nutrients, vol. 4, 396 pp., U.S. Gov. Print. Off., Washington, D. C.

Gregg, W. W., M. E. Conkright, P. Ginoux, J. E. O’Reilly, and N. W. Casey (2003), Ocean primary production and climate: Global decadal changes, Geophys. Res. Lett., 30(15), 1809, doi:10.1029/2003GL016889.

Kriest, I., S. Khatiwala, and A. Oschlies (2010), Towards an assessment of simple global marine biogeochemical models of different complexity, Prog. Oceanogr., 86(3-4), 337-360, doi:10.1016/j.pocean.2010.05.002.

Moisan, J. R., T. A. Moisan, and M. R. Abbott (2002), Modelling the effect of temperature on the maximum growth rates of phytoplankton popula- tions, Ecol. Modell., 153(3), 197-215, doi:10.1016/S0304-3800(02) 00008-X.

Muren, U., J. Berglund, K. Samuelsson, and A. Andersson (2005), Potential effects of elevated sea-water temperature on pelagic food webs, Hydrobiologia, 545, 153-166, doi:10.1007/s10750-005-2742-4.

Oschlies, A. (2001), Model-derived estimates of new production: New results point towards lower values, Deep Sea Res., Part II, 48(10), 2173-2197, doi:10.1016/S0967-0645(00)00184-3.

Plattner, G. K., F. Joos, T. F. Stocker, and O. Marchal (2001), Feedback mechanisms and sensitivities of ocean carbon uptake under global warming Tellus, Ser. B, 53(5), 564-592, doi:10.1034/j.1600-0889.2001.530504.x.

Pomeroy, L. R., and W. J. Wiebe (2001), Temperature and substrates as interactive limiting factors for marine heterotrophic bacteria, Aquat. Microb. Ecol., 23(2), 187-204, doi:10.3354/ame023187.

Riebesell, U., A. Kortzinger, and A. Oschlies (2009), Sensitivities of marine carbon fluxes to ocean change, Proc. Natl. Acad. Sci. U. S. A., 106(49), 20,602-20,609, doi:10.1073/pnas.0813291106.

Sarmiento, J. L., et al. (2004), Response of ocean ecosystems to climate warming, Global Biogeochem. Cycles, 18, GB3003, doi:10.1029/ 2003 GB002134.

Schartau, M., and A. Oschlies (2003), Simultaneous data-based optimization of a 1D-ecosystem model at three locations in the North Atlantic: Part I-Method and parameter estimates, J. Mar. Res., 61(6), 765-793, doi:10.1357/002224003322981147.

Schlitzer, R. (2002), Carbon export fluxes in the Southern Ocean: Results from inverse modeling and comparison with satellite-based estimates, Deep Sea Res., Part II, 49(9-10), 1623-1644, doi:10.1016/S09670645(02)00004-8.

Schlitzer, R. (2004), Export production in the equatorial and North Pacific derived from dissolved oxygen, nutrient and carbon data, J. Oceanogr., 60(1), 53-62, doi:10.1023/B:JOCE.0000038318.38916.e6.

Schmittner, A., A. Oschlies, H. D. Matthews, and E. D. Galbraith (2008), Future changes in climate, ocean circulation, ecosystems, and biogeochemical cycling simulated for a business-as-usual $\mathrm{CO}_{2}$ emission scenario until year 4000 AD, Global Biogeochem. Cycles, 22, GB1013, doi:10.1029/2007GB002953.

Steinacher, M., et al. (2010), Projected 21st century decrease in marine productivity: A multi-model analysis, Biogeosciences, 7(3), 979-1005, doi:10.5194/bg-7-979-2010.

Weaver, A. J., et al. (2001), The UVic Earth System Climate Model: Model description, climatology, and applications to past, present and future climates, Atmos. Ocean, 39(4), 361-428.

Westberry, T., M. J. Behrenfeld, D. A. Siegel, and E. Boss (2008), Carbonbased primary productivity modeling with vertically resolved photoacclimation, Global Biogeochem. Cycles, 22, GB2024, doi:10.1029/ 2007GB003078.

Wohlers, J., A. Engel, E. Zollner, P. Breithaupt, K. Jurgens, H. G. Hoppe, U. Sommer, and U. Riebesell (2009), Changes in biogenic carbon flow in response to sea surface warming, Proc. Natl. Acad. Sci. U. S. A., 106(17), 7067-7072, doi:10.1073/pnas.0812743106.

A. Oschlies and J. Taucher, Leibniz Institute for Marine Sciences at Kiel University (IFM-GEOMAR), Düsternbrooker Weg 20, D-24105 Kiel, Germany. (jtaucher@ifm-geomar.de) 